\title{
Clinical Profile and Outcome of Deliberate Self Poisoning Cases in Medical Wards
}

\author{
Indira Madhavan*, Santhosh L. K., Vinu Thomas \\ Department of Medicine, Government Medical College, Thrissur, India
}

Email address:

drindirarun76@gmail.com (I. Madhavan)

\section{To cite this article:}

Indira Madhavan, Santhosh L. K., Vinu Thomas. Clinical Profile and Outcome of Deliberate Self Poisoning Cases in Medical Wards. American Journal of Internal Medicine. Special Issue: Toxicology. Vol. 3, No. 6-1, 2015, pp. 5-9. doi: 10.11648/j.ajim.s.2015030601.12

\begin{abstract}
Non-fatal deliberate self-harm (DSH) and suicides are serious global health problems in many low- and middleincome countries including India. We conducted a cross sectional observational study in patients admitted with deliberate self harm in a tertiary care centre to identify the common agents used for poisoning in our area, to know the common clinical features and the outcome of such cases. Of the 200 patients observed, there were $114(57 \%)$ males and $86(43 \%)$ females. In the study group, 53 (13males, 40females) patients were adolescents, 85 (60 males, 25 females) were young, 29(16males, 13 females) were middle aged and 33 (25males, 8 females) were elderly. The pesticide group which included organophosphates, organochlorines, carbamates and pyrethroids constituted commonest substance used as poisoning agent $(39 \%, \mathrm{n}=78)$ followed by plant poisons $(28 \%, \mathrm{n}=55)$ which included yellow oleander, oduku leaves and abrus precatorius. Rodenticides $(10 \%, \mathrm{n}=20)$, benzodiazapines $(6 \%, n=11)$, kerosene $(5 \%, n==9)$ and paracetamol $(3 \%, n==6)$ were the other common exposure. Various drug combinations, copper sulphate, sulphuric acid, formic acid, fabric whitner, weedicides and homeopathic medications constitutes $11 \%(\mathrm{n}==21)$ of cases. Mortality of study population was $6 \%(\mathrm{n}==12,11$ men and 1 woman). Four patients expired after organophosphorus poisoning, four with carbamate poisoning, two with oduku, one each with rodenticide and yellow oleander poisoning. Pesticides and plant poisons are the common agents used for deliberate self harm in our study. Adoloscent and young persons are commonly involved in suicide attempts. Pesticides cause majority of deaths while plant and rodenticide poisonings can also be fatal.
\end{abstract}

Keywords: Deliberate Self Harm, Pesticides, Plant Poisons, Rodenticide Poisoning, Drug Overdosage

\section{Introduction}

Non-fatal deliberate self-harm (DSH) and suicides are serious global health problems in many low- and middleincome countries (1)(2) including India (3)(4). Agents used for DSH varies from place to place; in general drugs are the commonest agent in developed countries where as pesticides are common in developing and under developed countries (5)(6). Easy availability of pesticides makes it the common agent used for poisoning in India.

There are no precise data for occupational, accidental or deliberate self-poisoning globally due to lack of uniform surveillance. Throughout the world annual hospitalized persons for pesticide poisoning is estimated to be 3 million with $7.3 \%$ mortality.

Clinical features caused by many poisons may be non specific, but there will be some clues to diagnosis when all the features are taken together. Particular smell of the poison, local availability of plant poisons, easy access to over the counter medication etc will show marked regional variability.

Confirmation by chemical analysis of poison is not possible and not practical in the day to day clinical practice, as the facilities are not available and condition demands immediate management. History, circumstantial evidences and typical toxidromes helps in detecting the poison and prompt management. Data regarding the common agents used for DSH in a particular area and their common presenting features will be helpful in expeditious intervention.

\section{Methods}

We conducted a cross sectional observational study in 
patients admitted with deliberate self harm (DSH) in a tertiary care centre to identify the common agents used for poisoning in our area, to know the common clinical features and the outcome of such cases. All consecutive cases with DSH admitted on all Mondays over a period of one year were observed.

Nature of poisoning was confirmed from patient's clinical features, reference letter and/or from the bottle of poison produced. Patients are initially resuscitated in the emergency department and standard treatment was provided according to our hospital guidelines. Specific antidotes were given according to the poison exposed. Gastric lavage, activated charcoal and other supportive care were provided in appropriate cases. Demographic features of the patients, presenting clinical symptoms and signs were noted. Patients were followed up till recovery or death. Complications developed during hospital stay and in-hospital mortality were recorded.

\section{Results}

\subsection{Demographic Features}

Of the 200 patients observed, there were 114(57\%) males and $86(43 \%)$ females. Mean age (SD) of study population was 37.6 years $( \pm 15)$. In the study group, 53 (13males, 40females) patients were adolescents, 85 (60 males, 25 females) were young, 29(16males, 13 females) were middle aged and 33 (25males, 8females) were elderly (Table 1).

Table 1. Demographic features of study group.

\begin{tabular}{llll}
\hline Age & Male & Female & Total \\
\hline$\leq 18$ & 13 & 40 & 53 \\
$19-44$ & 60 & 25 & 85 \\
$45-59$ & 16 & 13 & 29 \\
$\geq 60$ & 25 & 8 & 33 \\
\hline
\end{tabular}

\subsection{Agents Used}

The pesticide group which included organophosphates, organochlorines, carbamates and pyrethroids constituted commonest substance used as poisoning agent $(39 \%, \mathrm{n}=78)$ followed by plant poisons $(28 \%, \mathrm{n}=55)$ which included yellow oleander, oduku leaves and abrus precatorius. Rodenticides $(10 \%, \mathrm{n}=20)$, benzodiazapines $(6 \%, \mathrm{n}=11)$, kerosene $(5 \%, n==9)$ and paracetamol $(3 \%, n==6)$ were the other common exposure. Various drug combinations, copper sulphate, sulphuric acid, formic acid, fabric whitner, weedicides and homeopathic medications constitutes $11 \%$ $(n==21)$ of cases.

Of pesticides, 36 were carbamate, 22 were organophosphate, 16 were pyrethroid and 4 were organochloride. Of plant poisons 29 were Oduku, 21 were yellow oleander and 5 were abrus. Males predominated in exposure to pesticides and rodenticides while females predominated in exposure to plant poisons, benzodiazapines and miscellaneous including multiple drugs (Table 2).
Table 2. Compounds used for DSH.

\begin{tabular}{lll}
\hline $\begin{array}{l}\text { Compound } \\
\text { consumed }\end{array}$ & $\begin{array}{l}\text { Number of patients } \\
\text { admitted }\end{array}$ & $\begin{array}{l}\text { Number of patients } \\
\text { expired }\end{array}$ \\
\hline Organophosphorus & 22 & 4 \\
Carbamates & 36 & 4 \\
Organochlorine & 4 & 0 \\
Pyrethroid & 16 & 0 \\
Oduku & 29 & 2 \\
Yellow oleander & 21 & 1 \\
Abrus precatorius & 5 & 0 \\
Rodenticide & 20 & 1 \\
Benzodiazapines & 11 & 0 \\
Paracetamol & 6 & 0 \\
Kerosene & 9 & 0 \\
Miscellaneous & 21 & 0 \\
\hline
\end{tabular}

\subsubsection{Pesticides}

Chlorpyrifos was the commonest organophosphorus compound $(\mathrm{n}=10,45.5 \%)$ exposed. Carbofuran was the commonest carbamate used $(\mathrm{n}==28,77.8 \%)$. The common symptoms observed in the cholinergic insecticide group were nausea and vomiting in 55 patients $(94.9 \%)$, breathlessness in $39(66.7 \%)$ patients, altered sensorium in 29 ( 50\%) patients, abdominal discomfort in $12(21.3 \%)$ patients, urinary incontinence in 23 patients $(26.7 \%)$, seizures in four ( $6.41 \%)$ patients and diarrhea in eight (14.14\%) patient. The common signs were smell of kerosene in $50(86 \%)$ patients, oronasal frothing in $28(48.7 \%)$ patients, miosis in 30 patients(52\%), fasciculation in 18 patients(31\%), hypotonia in 17 patients (30\%), diminished deep tendon reflexes 16 patients(27\%), bradycardia in 10 patients $(16.67 \%)$, tachycardia in 8 patients $(14.1 \%)$, hypotension in 6 patients and pulmonary oedema in 29 patients $(50 \%)$. Complications observed were aspiration pneumonia in four, critical care neuropathy in one and hematemesis in one patient. $8.9 \%$ patients $(n=5)$ developed intermediate syndrome and $21.7 \% \quad(n=13)$ developed respiratory failure.

\subsubsection{Yellow Oleander}

Common symptoms in yellow oleander poisoning were vomiting in 17 patients, dizziness/sycope in 7(33\%), tiredness in 7 (33\%), palpitation in $6(28 \%)$, abdominal pain in $4(19 \%)$, drowsiness in $3(15 \%)$ and asymptomatic in two. Signs observed were bradycardia in $12(57 \%)$ and hypotension in 5 (23\%). Normal ECG was seen in $19.1 \%$ of patients $(n=4)$. Other ECG changes observed were sinus bradycardia in $12(57 \%), 1^{\text {st }}$ degree AV block in five (23.8\%), digitalis effect in four $(19.1 \%), 2^{\text {nd }}$ degree AV block in two $(9.5 \%)$, atrial fibrillation in one $(4.8 \%)$, sinus block in one $(4.8 \%)$, sinus arrest in one $(4.8 \%)$, sine wave pattern in one $(4.8 \%)$, tall 't'wave in one $(4.8 \%)$ and ' $u$ ' waves in one (4.8\%). Eight patients had hyperkalemia and one had hypokalemia (Table 3).

\subsubsection{Oduku}

Major symptoms of oduku poisoning were vomiting in 22 patients $(75 \%)$. Other symptoms were tiredness in $13(44 \%)$, abdominal pain in $6(20 \%)$, dizziness/sycope in $3(10 \%)$, 
drowsiness in $2(7 \%)$ and breathlessness in $2(6 \%)$. Signs observed were bradycardia in $6(20 \%)$, tachycardia in $3(10 \%)$ of patients, hypotension in $2(6 \%)$, bradypnoea in four patients (13.8\%). ECG of 18 patients $(62 \%)$ was normal. Presence of ' $u$ ' waves was seen in four patients $(13.8 \%)$. Other ECG findings were seen in one patient each which included first degree AV block, right bundle branch block, sine wave pattern, ST depression, sinus arrest, sinus tachycardia and tall't' wave(Table 3).

Table 3. ECG changes in plant poisons.

\begin{tabular}{lll}
\hline & $\begin{array}{l}\text { Oleander poisoning } \\
\text { N=21 }\end{array}$ & $\begin{array}{l}\text { Oduku poisoning } \\
\mathbf{N}=29\end{array}$ \\
\hline Sinus bradycardia & $12(57 \%)$ & 0 \\
Firs degree AV block & $5(23.8 \%)$ & $1(3.5 \%)$ \\
Second degree AV block & $2(9.5 \%)$ & 0 \\
Atrial fibrillation & $1(4.8 \%)$ & 0 \\
Sinus block & $1(4.8 \%)$ & 0 \\
Sinus arrest & $1(4.8 \%)$ & $1(3.5 \%)$ \\
Sine wave pattern & $1(4.8 \%)$ & $1(3.5 \%)$ \\
'u' wave & $1(4.8 \%)$ & $4(13.8 \%)$. \\
Tall 't' wave & $1(4.8 \%)$, & $1(3.5 \%)$ \\
RBBB & 0 & $1(3.5 \%)$ \\
ST depression & 0 & $1(3.5 \%)$ \\
Sinus tachycardia & 0 & $1(3.5 \%)$ \\
Normal & $4(19.1 \%)$ & $18(62 \%)$ \\
Digitalis effect & $(19.1 \%)$, & 0 \\
\hline
\end{tabular}

\subsubsection{Rodenticides}

In the rodenticide group, 17 patients were exposed to norbromide compounds and 3 had phosphorus containing compounds. Common symptoms were nausea and vomiting in $75 \%(n=15)$, abdominal pain in $25 \%(n=5)$, jaundice in $5 \%$ $(n=1)$ and asymptomatic in $20 \%(n=4)$. At the time of presentation, examination findings were normal except hypotension in one patient and hepatic encephalopathy in another patient who presented 72 hours post-exposure. Findings developed during hospital stay within three to five days post-exposure which included jaundice in $60 \%(12$ patients), right hypochondrial pain in five $(25 \%)$ and tender hepatomegaly in four $(20 \%)$.

\subsubsection{Others}

Features seen in benzodiazepine poisoning included sleepiness in 10 patients $(90.9 \%)$, urinary incontinence in three $(27.2 \%)$ patients, hypotonia in $6(54.5 \%)$ patients, sluggish deep tendon reflexes in four (36\%) patients, bradycardia in seven $(63 \%)$ patients and hypotension in one $(9.1 \%)$ patient.

All nine patients with kerosene poisoning had vomiting. Other features included cough in six $(66 \%)$ patients, abdominal discomfort in $3(33.3 \%)$, seizure in one $(11.1 \%)$ patient, rhonchi in $5(55.6 \%)$, crepitations in $3(33.3 \%)$.

\subsection{Outcome}

Mortality of study population was $6 \%(n==12,11$ men and 1 woman). Four patients expired after organophosphorus poisoning, four with carbamate poisoning, 2 with oduku, 1 each with rodenticide and yellow oleander poisoning.

\section{Discussion}

In our study agents common agents used for DSH are pesticides followed by plant poisons.Pesticides were the common agents used as seen with many Indian studies. Predominance of carbamate among the pesticides in our study may be a regional variation as organophosphates are the common agents in other studies. A stdy from All India Institute of Medical sciences, New Delhi also showed a predominence $\mathrm{f}$ carbamateds amongthe pesticide group, but poisoning due to drugs predominated in that sudy(7). Usage of plant poisons, especially oduku leaves is another regional peculiarity which is common is certain parts of South India only.

Adolescents and young people are the common group admitted with DSH. In general there was male predomonence, but females predominated in adolescent age group. Most active age groups are involved in DSH. This is in concordance with previous literature (7-10).

Cholinergic symptoms are well described in organophosphoru and carbamate poisoning. Though muscarinic features like miosis, bradycardia and frothing are pathognomonic, nicotinic features like mydriasis and tachycardia are also described. We observed tachycardia in few patients with cholinergic poisoning, but mydriasis due to poisoning was not seen. Both organophosphorus and carbamate are found to be equally harmful in terms of mortality and morbidity (11). Respiratory failure, shock, aspiration pneumonia and intermediate syndrome were the common complications described in literature (12).

Deliberate self harm of oleander seeds is a popular method of suicide in Sree Lanka and in south India (13). They cause digitalis like effect on heart. Various arrhythmias and conduction defects are characteristic of oleander poisoning. Clinical symptoms start within 2 to 3 hours of ingestion (14).These are nausea, vomiting, frothy salivation , abdominal pain, mydriasis, tingling, numbness, restlessness, bradycardia, arrhythmia, hypotension and coma(15). Occasionally jaundice and respiratory failure may occur (16)(17). Dizziness, tiredness and palpitation were the common symptoms we observed. Bradycardia and hypotension responded to atropine except in one patient who expired.

Oduku(C.collinus) poisoning appears to be a problem of rural population, preferred by young women as a method of deliberate self harm. A study on acute poisoning in villagers reported that $87.8 \%$ of women consumed plant poison, $44.5 \%$ of whom consumed C.collinus . This female preponderance with C.collinus poisoning is evident in most clinical studies(18). Easy availability and free access to the plants are probably the reason why the women prefer this method of deliberate self harm. The predominant signs and symptoms include nausea, vomiting, abdominal pain, and feeble pulse. Tachypnoea, tachycardia and shortness of breath, 
hyperpyrexia, muscle cramps and cardiac conductive defects. Our observations are also consistent with the literature. Also bradycardia, hypotension and bradypnoea were noted as presenting features which required atropine and ventillatory support.

Currently used rodenticides include yellow phosphorus, and warfarin like anticoagulants(19)(20). Yellow phosphorous can get absorbed through skin, mucus membrane, respiratory and gastrointestinal epithelium. After absorption, it is distributed to all tissues, particularly the liver, and the peak level is reached after 2 to 3 hours of toxic oral ingestion. Phosphorus is a general protoplasmic poison causing cardiac, hepatic, renal, and multiorgan failure. But usually patient may be asymptomatic at the time of admission and systemic involvement may be evident 12 to 24 hours post exposure as seen in our case series. Yellow phosphorus is highly lethal and one out of three patients expired in our series.

Drugs constituted a smaller percentage when compared to other agents used(21). Among drugs, benzodiazepine and acetaminophen constituted the major number while multiple drug combinations were also used. Drugs were mainly used by women and were not taken in fatal doses. Inhibitory effect of GABA is potentiated by benzodiazapines by binding to the GABA receptor complex and increasing the frequency of opening of chloride channels in response to GABA stimulation(22). Benzodiazepines are lipid soluble drugs which are readily absorbed and exhibit 85 to $99 \%$ protein binding in the plasma American Association of Poison Control Centers (AAPCC) reports that acetaminophen is one of the most common pharmaceuticals associated with both intentional and unintentional poisoning and toxicity. After initial asymptomatic period, patients who have taken an overdose of acetaminophen will show clinical end-organ toxicity after 24-48 hours of ingestion. Minimum toxic doses of acetaminophen for a single ingestion, with significant risk of hepatotoxicity, in adults is 7.5-10 g.

Hydrocarbons (kerosene) produce CNS excitation in low doses and depression in high doses(23). Rarely coma and seizures occur. Psychosis, cerebral and cerebellar atrophy, encephalopathy, and peripheral neuropathy can result from chronic inhalation. Other effects include nausea, vomiting, abdominal pain, hepatitis, renal tubular acidosis, acute hepatic or renal failure, and rhabdomyolysis(24). Kerosene didn't cause any mortality in our series though seizure and respiratory symptoms were observed.

Acid poisoning and few other miscellaneous agents were also observed in our series, but were less in number. None of them caused mortality.

Overall mortality of study population was $6 \%$ which is smaller compared to other Indian studies, but common cause of death are pesticides which is similar to previous studies. Plant poisons and rodenticides also contributed to mortality, but drugs and hydrocarbons were not fatal in our study population.

\section{Conclusion}

Pesticides and plant poisons are the common agents used for deliberate self harm in our study. Adolescents and young persons are commonly involved in suicide attempts. Pesticides cause majority of deaths while plant and rodenticide poisonings can also be fatal.

\section{References}

[1] Gunnell D, Eddleston M. Suicide by intentional ingestion of pesticides: a continuing tragedy in developing countries. International Journal of Epidemiology. IEA; 2003. p. 902-9.

[2] Gunnell D, Eddleston M, Phillips MR, Konradsen F. The global distribution of fatal pesticide self-poisoning: systematic review. BMC Public Health . 2007 Jan; 7: 357.

[3] Bose TK, Basu RK, Biswas B, De JN, Majumdar BC, Datta S. Cardiovascular effects of yellow oleander ingestion. J Indian Med Assoc. 1999 Oct; 97(10): 407-10.

[4] Gautami S, Sudershan RV, Bhat R V., Suhasini G, Bharati M, Gandhi KPC. Chemical poisoning in three Telengana districts of Andhra Pradesh. Forensic Sci Int. Elsevier; 2001 Nov 1; 122(2-3): 167-71.

[5] Manuel C, Gunnell DJ, van der Hoek W, Dawson A, Wijeratne IK, Konradsen F. Self-poisoning in rural Sri Lanka: small-area variations in incidence. BMC Public Health. 2008 Jan; 8: 26.

[6] Eddleston M, Buckley NA, Eyer P, Dawson AH. Management of acute organophosphorus pesticide poisoning. Lancet. Lancet Publishing Group; 2008; 371(9612): 597-607.

[7] Das RK. Epidemiology of Insecticide poisoining at A.I.I.M.S Emergency Services and role of its detection by gas liquid chromatography in diagnosis. Medico update. 2007; 7: 49-60.

[8] Unnikrishnan B, Singh B, Rajeev A. Trends of acute poisoning in South Karnataka. Kathmandu Univ Med J (KUMJ) 2005; 3: 149-54.

[9] Dash SK, Aluri SR, Mohanty MK, Patnaik KK, Mohanty S. Sociodemographic profile of poisoning cases. JIAFM. 2005; 27: $133-8$.

[10] Kora SA, Doddamani GB, Halagali GR, Vijayamahantesh SN, Umakanth B. Sociodemographic Profile of the Organophosphorus Poisoning Cases in Southern India. 2011; 5(5): 953-6.

[11] Eddleston M, Mohamed F, Davies JOJ, Eyer P, Worek F, Sheriff MHR, et al. Respiratory failure in acute organophosphorus pesticide self-poisoning. QJM. 2006 Aug; 99(8): 513-22.

[12] Indira M, Andrews MA, Rakesh TP. Incidence, predictors, and outcome of intermediate syndrome in cholinergic insecticide poisoning: a prospective observational cohort study. Clin Toxicol (Phila). 2013 Nov; 51(9):838-45.

[13] Eddleston M, Persson H. Acute plant poisoning and antitoxin antibodies. J Toxicol Clin Toxicol. 2003 Jan; 41(3): 309-15.

[14] Eddleston M, Warrell DA. Management of acute yellow oleander poisoning. QJM. 1999 Sep 1; 92(9): 483-5. 
[15] Shumaik GM, Wu AW, Ping AC. Oleander poisoning: Treatment with digoxin-specific fab antibody fragments. Ann Emerg Med; 1988 Jul 7; 17(7): 732-5.

[16] Pirasath S, Arulnithy K. Yellow oleander poisoning in eastern province: an analysis of admission and outcome. Indian J Med Sci; 2013 Jan 1; 67(7-8): 178-83.

[17] Rajapakse S. Management of yellow oleander poisoning. Clin Toxicol (Phila). 2009 Mar; 47(3): 206-12.

[18] Cleistanthus collinus poisoning: an effective management with multidose activated charcoal. Available from: http://allsubjectjournal.com/vol2/issue1/PartF/pdf/20.1.pdf.

[19] Parsons BJ, Day LM, Ozanne-Smith J, Dobbin M. Rodenticide poisoning among children. Aust N Z J Public Health [Internet]. 1996 Oct; 20(5): 488-92.

[20] Kruse JA, Carlson RW. Fatal rodenticide poisoning with brodifacoum. Ann Emerg Med. 1992 Mar; 21(3): 331-6.
[21] Eddleston M, Gunnell D, Karunaratne A, de Silva D, Sheriff MHR, Buckley $\mathrm{N}$ a. Epidemiology of intentional selfpoisoning in rural Sri Lanka. Br J Psychiatry. 2005 Dec; 187: $583-4$.

[22] Chern C-H, Chern T-L, Wang L-M, Hu S-C, Deng J-F, Lee C$\mathrm{H}$. Continuous flumazenil infusion in preventing complications arising from severe benzodiazepine intoxication. Am J Emerg Med. Elsevier; 1998 May 5; 16(3): 238-41.

[23] Reed RP, Conradie FM. The epidemiology and clinical features of paraffin (kerosene) poisoning in rural African children. Ann Trop Paediatr. 1997 Mar 1; 17(1): 49-55.

[24] Wolfe BM, Brodeur AE, Shields JB. The role of gastrointestinal absorption of kerosene in producing pneumonitis in dogs. J Pediatr. 1970 Jun; 76(6): 867-73. 